\title{
Determinants of individual willingness to pay for quality water supply: the case of Wonji Shoa Sugar Estate, Ethiopia
}

\author{
S. Wondimu ${ }^{1} \&$ W. Bekele ${ }^{2}$ \\ ${ }^{1}$ Industrial Projects Service, Addis Ababa, Ethiopia \\ ${ }^{2}$ Dire Dawa University, Ethiopia
}

\begin{abstract}
This paper analyses the determinants of households' willingness to pay (WTP) for quality water supply, using the contingent valuation method (CVM). The study was conducted with randomly selected households in the factory villages of Wonji Shoa Sugar Estate, Ethiopia. The value elicitation method used is a close ended format questionnaire with additional close ended format, and open ended follow up questions which is closer to the market scenario respondents are familiar with. The empirical model used in this study is the Tobit model. The result of the study revealed that income of the household, education level of the respondent, reliability on existing water supply, respondent perception about quality of the existing water supply, household family size and age of the respondent are significant variables that explain WTP. The mean WTP for quality water supply is found to be $\$ 0.025$ per 20 litres which is well above the current tariff rate of the Oromiya regional government in Ethiopia.
\end{abstract}

Keywords: willingness to pay, contingent valuation study, Wonji Shoa Sugar Estate.

\section{Introduction}

Adequacy and quality are crucial for household water supply. Safe drinking water is an essential component of primary health care and has a vital role in poverty alleviation. There is a positive correlation between increases national income and the portion of population with access to improved water supply. According to the 1994 World Bank Report [1] an increase of 0.3 percent investment in household access to safe drinking water generates one percent 
increase in GDP. Unreliable supply and shortage of water affects the life of human beings in various ways. According to the WHO and UNICEF 2010 progress report [2] on sanitation and drinking water, of the six billion people on earth, 884 million people do not get their drinking water from improved sources, and almost all of them live in developing regions. Sub Saharan Africa accounts for over a third of that number, and is lagging behind in progress toward the Millennium Development Goal (MDG) target, with only 60 percent of the population using an improved source of drinking water despite an increase of 11 percentage points since 1990 .

Ethiopia, like any other developing countries has many constraints to make potable water easily accessible. Only 38 percent of the total population and 26 percent of rural population have access to safe and clean water [2]. Moreover, Ethiopia is off track to meet the MDG target i.e. halving the portion of the population without sustainable access to safe drinking water by 2015 .

To improve access to safe clean water the government of Ethiopia has prepared a water and sanitation policy document as an integral part of the country's water management policy. This document clearly indicates the right of every Ethiopians to get access to adequate and quality water to satisfy their basic needs in order to achieve rapid socio-economic development through better health care and productivity [3]. In this document to improve the financial base needed for water development projects and other public undertakings a cost recovery mechanism is cited as one of the basic water law policies.

Wonji Shoa Sugar Estate (WSSE) is an old agro industry located in the boundary of the Great African Rift Valley with total population of 22,635. The community of the estate and its adjacent area largely depend on ground water with high fluoride content ranging from $2.4 \mathrm{mg} /$ liter to $18 \mathrm{mg} /$ liter which is by far greater than the maximum permissible concentration of $1.5 \mathrm{mg} /$ liter of fluoride content in drinking water [4]. The excessive fluoride in drinking water has been a known cause for dental and skeletal fluorosis in the community. One potential way of tackling the problem is through the provision of clean tap water supply. However, provision of clean water involves costs and the community need to be willing to share costs. This requires understanding the inhabitants' willingness to pay for a better and cleaner water supply. In the absence of a market for this environmental service, we ask people what they do in a hypothetical situation. This method is known as contingent valuation; involve obtaining direct information from individuals about their willingness to pay (WTP) for a change in quality. Thus, adequate knowledge is required to understand the household water demand behaviour and what factor determine their willingness to pay. This paper therefore tries to asses the determinants of the willingness to pay for quality water service in WSSE.

\section{Method}

\subsection{Contingent valuation method}

Water lies between the two extremes of purely public and private goods. Given the nature of the goods, we don't know how much value society attach to 
improvement for water quality. We use contingent valuation which is a direct valuation method that uses a survey to elicit the value individuals attach to nonmarketed goods. Since we are proposing to improve the quality of water to be used by the society, the WTP format is used, given the property right structure (Mitchell and Carson [5]). The relevant welfare measure is therefore the Hecksian compensating surplus.

A number of theoretical and methodological issues and criticisms have been raised concerning the application of the contingent valuation method in general and in valuation in developing countries in particular. A look into literatures indicates that, at least at the theoretical level, a large number of criticisms, particularly those related to economic theory, are in one way or other linked with problems in details of specific studies, such as how the questionnaire was prepared and data collected and analysed. Even such issues as insensitivity of values to the scope of the goods are, to some degree, linked how well and carefully the studies are conducted [6-8].

A common value elicitation method is the dichotomous choice format. As an alternative to dichotomous choice questions, the use of an open ended follow up question to binary (close ended) one has been proposed and used by Mitchell Carson [5]. Moreover, Green et al. [9] argue that a binary question with open ended follow up question provides far information on WTP and information on plausibility of responses than alternatives such as the double referendum method. Moreover, while the problem of high non-response rate would be minimized when open ended questions are preceded by close ended ones (and, perhaps, in person interviews used), the idea of unfamiliarity with the market scenario is not always a problem particularly when open-ended questions are presented as a follow-up to binary question. In fact, such an elicitation format is closer to what respondents in Ethiopia and other developing countries are used to than the referendum method in which the respondents, as buyers of a commodity, would first expect the price to be stated by the seller and then after some bargaining would decide on the final amount he or she would pay.

\subsection{Sampling design}

In this study, a two stage simple random sampling technique is used to select 126 sample households. During the initial step of sampling out of 11 villages of the estate ( 2 factory villages and 9 plantation villages), one factory villages and three plantation villages were randomly selected. These are Wonji factory village and $\mathrm{R}_{3}, \mathrm{~L}_{3}$, and $\mathrm{E}_{3}$ from plantation village in the final stage $91,12,11,12$ households were randomly selected from Wonji factory village, $\mathrm{R}_{3}, \mathrm{~L}_{3}$ and $\mathrm{E}_{3}$ respectively using proportional to size sampling technique.

\subsection{Survey design and implementation}

Before designing the contingent valuation survey method a focus group discussion was made in the early September 2008. The focus group meeting allowed the researchers to identify the water supply problems of the enterprise and to come up with first draft questionnaire having three parts. The first section 
deals with household water use practice, present status of water supply situation, water supply period, status of water related disease and household evaluation of existing water supply situation such as quality and reliability. The second section consists of contingent valuation question. In this section a hypothetical market scenario was designed as one of the best basic component of the survey questionnaire based on the improvement of the existing water supply situation. In this section of the questionnaire to assess households' willingness to pay, the dichotomous choice format questions, with one additional dichotomous choice and with an open ended follow up questions was used. In the third part of the questionnaire, questions related with socio economic and demographic characteristics of the households such as education level and age of the respondent, family size, average monthly income and the like were stated, adopting the Mitchell and Carson method [5].

After designing the draft questionnaire, pre-testing was conducted through focus group discussions with the estate water supply section head and seventeen randomly selected households. In the pre-test, an open ended question was used for elicitation of the WTP amount, which asked the respondents the maximum amount they would be willingness to pay for the service per 20 litres container.

The purpose of the pre test was to make some possible modifications in the design of the questionnaire of the main survey, to choose appropriate payment vehicle and to obtain starting values (as close-ended with an open-ended follow up format is used) so that the objective of the survey can be met.

Based on the pre-test, the order of the questionnaire was restructured, making questions on household characteristics (particularly question with economic characteristics, income) to appear in the last part. The willingness to pay section also was polished so that it becomes easier to understand by both the respondents and the interviewers. The payment vehicle is chosen to be monthly tariff based on the pre test result. The starting bid value was also obtained from the pre test conducted with open ended questions. In the pre-test, six households from plantation villages (E3 and R3) are willing to pay $(\$ 0.004, \$ 0.009, \$ 0.009$, $\$ 0.009, \$ 0.013, \$ 0.009 / 20$ litres). Hence $\$ 0.009$ is used as one starting value. Six households from factory villages are willing to pay $(\$ 0.022, \$ 0.022, \$ 0.044$, $\$ 0.031, \$ 0.035, \$ 0.022$ per 20 litres). Hence, the average $\$ 0.022$ is used as second starting point. Five relatively rich households from factory village are willing to pay $(\$ 0.044, \$ 0.066, \$ 0.044, \$ 0.088, \$ 0.088 / 20$ litres). Hence, the average $\$ 0.044$ is used as the third starting value. The starting prices $(\$ 0.009$, $\$ 0.022$ and $\$ 0.044$ ) were equally and randomly distributed in all the villages interviewed. Households interviewed in the pre test were not included in the main survey.

A total of four enumerators two of them diploma holders and two collage students and two supervisors including one of the researchers participated in the main survey. For this purpose, two day training was given to enumerators on the nature of the survey and how to administer it. The survey was conducted from October 15 up to November 5, 2008. 


\subsubsection{Hypothetical scenario}

A hypothetical market scenario was designed based on improvement of existing water supply situation of the sugar estate.

Without project: WSSE supply potable water to their employees free of charge since its establishment. But the quality and reliability of water supply is not up to standard. For instance, the fluoride content of water ranging from $2.4 \mathrm{mg} /$ liter up to $18.8 \mathrm{mg} /$ litre is by far greater than the permissible concentration of fluoride in drinking water. This excessive concentration of fluoride causes dental fluorosis in children and skeletal fluorosis in adults in the health of the society (figure 1). This leads to additional cost for medication and early retirement from jobs. The prevalence rate of dental fluorosis ranges between $69 \%$ and $98 \%$. More over, the occurrences of disease related with poor quality of water results in fewer working hours, less productivity and hence fall in income and loss of life in the worst case.

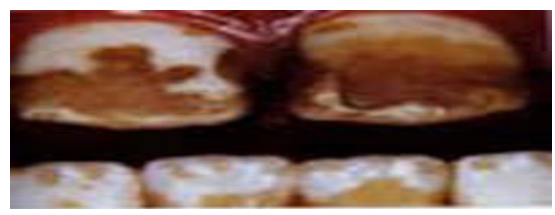

Figure 1: Severe fluorosis.

With project: to alleviate the above problem the Wonji Shoa Sugar Estate is planning to provide quality and reliable water supply to their employees. Quality and reliable water supply means provision of a good quality of water which is safe for health, the water is available for use at any time and collection of water need not take much time and effort. The investment cost will be covered by the estate and extrapolate to the users through by charging a water bill for their consumption.

\section{Empirical model}

The study of willingness to pay for quality water supply based on dichotomous choice format is followed by open ended question format that finally produce continuous value of the respondent including zero. Hence, the Tobit model was used for analysing the determinants for WTP and the maximum amount of money the individual willing to pay. This model has an advantage over other discrete choice models (Linear probability model, logistic, and probit) in that, it reveals both the probability of willingness to pay and its maximum WTP for the respondents.

Following Maddala [10] and Johnston and Dindaro [11], the Tobit model can be defined as:

$$
\begin{array}{r}
\operatorname{MWTP}_{i}{ }^{*}=\beta_{0}+\beta^{\prime} X_{i}+\varepsilon_{i} \\
\operatorname{MWTP}_{i}=\operatorname{MWTP}_{i}^{*}{ }^{*} \text { ifMWTP }{ }_{i}^{*} \succ 0 \\
=0 \text { if } \text { MWTP }_{i}{ }^{*} \leq 0
\end{array}
$$


where MWTP is a vector of willingness to pay which is censored at $0 ; \mathrm{X}$ is a matrix of explanatory variables that are hypothesized to influence willingness to pay; $\beta$ is vector of unknown parameters to be estimated corresponding to the matrices of explanatory variables $\mathrm{X} ; \varepsilon$ is error term which could be independently and normally distributed with mean zero and common variance sigma square and; $M W T P{ }_{i}^{*}$ is a latent variable corresponding to MWTP. Note that values of MWTP observed when it is greater than zero.

It may not be sensible to interpret coefficients of a Tobit in the same way as one interprets coefficients in an uncensored linear model [11]. Hence, one has to compute the derivatives of the estimated Tobit model to predict the effects of changes in the exogenous variables.

According to Scott Long [12], McDonald and Moffit the following techniques could be used to decompose the effects of explanatory variables into WTP and on the amount of WTP. The marginal effect of an explanatory variable on the expected value of the dependent variable is:

$$
\frac{\partial E\left(M W T P_{i}\right)}{\partial X_{i}}=F(z) \beta^{\prime}
$$

where, $\frac{\beta^{\prime} X_{i}}{\delta}$ is denoted by z, following Maddala [10].

The change in the probability of willingness to pay as independent variable $X_{i}$ changes is:

$$
\frac{\partial F(Z)}{\partial X_{i}}=f(z) \frac{\beta^{\prime}}{\delta}
$$

The change in the amount of willingness to pay with respect to a change in explanatory variable among individuals who are willing to pay is:

$$
\frac{\partial E\left(M W T P_{i} / M W T P_{i}^{*} \succ 0\right)}{\partial X_{i}}=\beta^{\prime}\left[1-Z \frac{f(z)}{F(z)}-\left(\frac{f(z)}{F(z)}\right)^{2}\right]
$$

where, $F(z)$ is the cumulative normal distribution of $Z, f(z)$ is the value of the derivative of the normal curve at a given point (i.e., unit normal density), $\mathrm{Z}$ is the $Z$ - score for the area under normal curve, $\beta^{\prime}$ is the vector of Tobit maximum likelihood estimates and $\delta$ is the standard error of the error term.

\section{Results and discussion}

\subsection{Data description}

The descriptive statistics for variables included in the estimation are presented in table 1. Expecting that household size and age could affect willingness to pay, these were included as regressors. Income, education level of the household head and sex are another set of variables that are expected to influence willingness to pay. We also included cases of disease in households and reliability of existing 
source of water, perception about quality of existing water supply and type of employment. To test whether or not the stated willingness to pay is sensitive to the bid value randomly assigned to respondents, bid value was also included. Moreover, we also report the mean willingness to pay of the sampled household.

Table 1: $\quad$ Descriptive statistics.

\begin{tabular}{|l|c|c|c|c|}
\hline Variable & Mean & $\begin{array}{c}\text { Std. } \\
\text { dev. }\end{array}$ & Min. & Max. \\
\hline Sex & 0.66 & 0.48 & 0 & 1 \\
\hline Education level & 0.75 & 0.44 & 0 & 1 \\
\hline Household size & 4.59 & 1.82 & 1 & 10 \\
\hline Age of the respondent & 41.63 & 8.45 & 28 & 60 \\
\hline Household income per month in US dollar & 149.58 & 82.43 & 25 & 303 \\
\hline Perception about quality of existing water & 0.89 & 0.31 & 0 & 1 \\
\hline Case of disease in household & 0.83 & 0.38 & 0 & 1 \\
\hline Type of employment & 0.78 & 0.42 & 0 & 1 \\
\hline Reliability of the existing water source & 0.84 & 0.37 & 0 & 1 \\
\hline Bid value in US dollar & 0.02 & 0.13 & 0.01 & 0.04 \\
\hline Willingness to pay in US dollar & 0.025 & 0.019 & 0 & 0.07 \\
\hline
\end{tabular}

\subsection{Determinate analysis}

Estimate of the parameters of the variables expected to affect willingness to pay for quality water supply are shown in table 2 . The dependent variable is a continuous variable that individuals respond as maximum willingness and ability to pay for the improvement service recalling the benefits expect out of it. A total 10 explanatory variables were considered in the econometric analysis, out of which six variables were found to significantly influence the individual willingness to pay for quality water supply.

The parameter estimate for the income variable was significant $(p<0.1)$ and positive, as expected, indicated that richer households are willing to pay more. Hence, income is a strong determinant in explaining willingness to pay and any attempt to introduce cost sharing for the provision of quality water should take in to account ability of the users in addition to their WTP. The marginal effect result presented in Table 3 shows that when the income of the household increase by $\$ 1$, it will increase the probability of willingness of a household to pay for quality water by $0.03 \%$. Also, when income of a household increase by $\$ 1$, the amount of cash the household could pay for quality water would increases by 0.016 cents, other factors being constant. The variable that measure age of the respondent had the expected negative parameter estimate, suggesting that older people have shorter planning horizon are willing to pay less than the younger generation. The marginal effect result shows that for each additional increase in age of the respondent, the probability of the willingness to pay for quality water supply will decrease by $0.079 \%$. Also, as the age of a respondent increases by one year, the amount of cash he is willing to pay for quality water may decrease by 0.4012 cents, ceteris paribus. 
Table 2: $\quad$ Maximum likelihood estimates of Tobit model.

\begin{tabular}{|l|l|}
\hline Variable & Estimated coefficients \\
\hline Constant & 10.4121 \\
& $(7.2964)$ \\
\hline Age of the respondent & $-0.4171^{* * *}$ \\
& 0.13679 \\
\hline Education level & $6.9243^{* *}$ \\
& $(3.2337)$ \\
\hline Sex & -0.3805 \\
& $(1.9475)$ \\
\hline Household size & $-2.8082^{* * *}$ \\
& $(0.5486)$ \\
\hline Perception about quality of & $13.0167^{* * *}$ \\
existing water source & $(4.4415)$ \\
\hline Reliability of the existing & $6.7383^{*}$ \\
water source & $(3.4436)$ \\
\hline Type of employment & -6.1514 \\
& $(4.0244)$ \\
\hline Household income & $0.0166^{* * *}$ \\
& $(0.0013)$ \\
\hline Case of disease in household & 0.0713 \\
& $(2.8570)$ \\
\hline Bid value & 0.0318 \\
& $(0.0557)$ \\
\hline
\end{tabular}

$* * *, * *, *$ indicates significance at $1 \%, 5 \%$ and $10 \%$ levels respectively. Figures in parentheses are standard errors.

Household size was found to have significant $(p<0.1)$ effect with a negative parameter estimates. This suggests that willingness to pay for quality water supply decreases as household size increases. This is perhaps because of the effect of availability of labour that can be used to collect from other source or the high opportunity cost using income for clean water supply due to high demand for food and other necessities in such families. The marginal effect result shows that when the family size of a household increases by one person, it will decrease the probability of willingness of a household to pay for quality water by $0.53 \%$. Similarly, when the family size of a household increases by one person, the amount of cash a household is willing to pay for quality water may decrease by 2.6992 cents, other factors being constant. Education level of the respondent was another variable found to be significant $(p<0.05)$. Since the parameter estimate is positive, it implies that educated respondents tend to be willing to pay more than uneducated ones. This is perhaps because an educated household tend to be more aware about the impact of dental and skeletal fluorosis. The marginal effect of the result shows that the respondent being educated, the probability of willingness to pay for quality water increases by 
$2.24 \%$. Also, as the years of education increases by one year, the amount of cash the household is willing to pay for quality water may increase by 6.4672 cents, other factors held constant.

Reliability of the existing water supply was found to have significant $(p<0.1)$ effect with a negative parameter estimates. This means that as respondents feels the existing water supply is unreliable; he/she become more willing to pay for improvement. This is perhaps because searching water from another source is time taking and tiresome. According to table 3, the marginal effect of the variable shows that those respondents having reservation on the reliability of the existing water source will have $2.48 \%$ more probability of paying for quality water supply than those who are satisfied. Also, respondents having reservation on reliability of the existing water supply, would pay 6.2336 cents more than those respondents satisfied with the existing source, being other variable held constant.

The coefficient for respondent perception about quality of water services has the expected sign and strongly significant $(\mathrm{p}<0.1)$. One possible reason could be those household who perceive the poor quality and health hazards of the current water service are likely to pay for improved water services than those households who don't perceive the problem with quality and related health hazards. The marginal effect of this variable reveals that respondents who perceived the existing water quality is poor have $10.13 \%$ more probability of paying for quality water supply compared to respondents who didn't recognize the quality of water. Also, respondents who perceived poor quality of water are

Table 3: Marginal effects of the explanatory variable on the amount of willingness to pay.

\begin{tabular}{|l|c|c|c|}
\hline $\begin{array}{l}\text { Explanatory } \\
\text { Variables }\end{array}$ & $\begin{array}{l}\text { Change in } \\
\text { probabilities as } \\
\text { independent } \\
\text { variable changes }\end{array}$ & $\begin{array}{l}\text { Change among } \\
\text { individuals who } \\
\text { are willing to pay }\end{array}$ & $\begin{array}{l}\text { Change } \\
\text { among } \\
\text { the whole }\end{array}$ \\
\hline Age of the respondent & -0.00079 & -0.40122 & -0.40985 \\
\hline Education level & 0.022438 & 6.467184 & 6.71049 \\
\hline Sex & -0.00071 & -0.36599 & -0.37374 \\
\hline Household size & -0.00534 & -2.69919 & -2.75722 \\
\hline $\begin{array}{l}\text { Perception about } \\
\text { quality of existing } \\
\text { water source }\end{array}$ & 0.101342 & 10.96319 & 12.05092 \\
\hline $\begin{array}{l}\text { Reliability of the } \\
\text { existing water source }\end{array}$ & 0.024783 & 6.233591 & 6.502169 \\
\hline Type of employment & -0.00694 & -6.00997 & -6.08532 \\
\hline Household income & 0.000317 & 0.015999 & 0.016344 \\
\hline $\begin{array}{l}\text { Case of disease in } \\
\text { household }\end{array}$ & 0.000137 & 0.068536 & 0.070019 \\
\hline Bid value & $6.06^{*} 10^{5}$ & 0.030607 & 0.031265 \\
\hline
\end{tabular}


willing to pay 10.9632 cents more for quality water than those who perceive the water quality is safe, ceteris paribus. The parameter estimate for staring price was positive but not significant suggesting that there is no significant starting point bias. This could be due to the care taken in conducting the survey work.

\subsection{Derivation of aggregate demand and estimation of consumer's surplus for quality water supply}

The aggregate demand for this study has been derived from WTP payment scenario. The aggregate demand curve is derived using the mid willingness to pay amount along the vertical axis and the number of households' willingness to pay at least that mid value per 20 litres container along the horizontal axis, (Figure 2). The figure shows the aggregate demand curve for the improvements in water supply services using the observations in the study. Any point on the curve shows all the households that prefer the improved water service but do not bid more than the corresponding value on the mid WTP axis. In order to get the demand in terms of quantity it just requires us to multiply the number of households by the average daily consumption of water at each point.

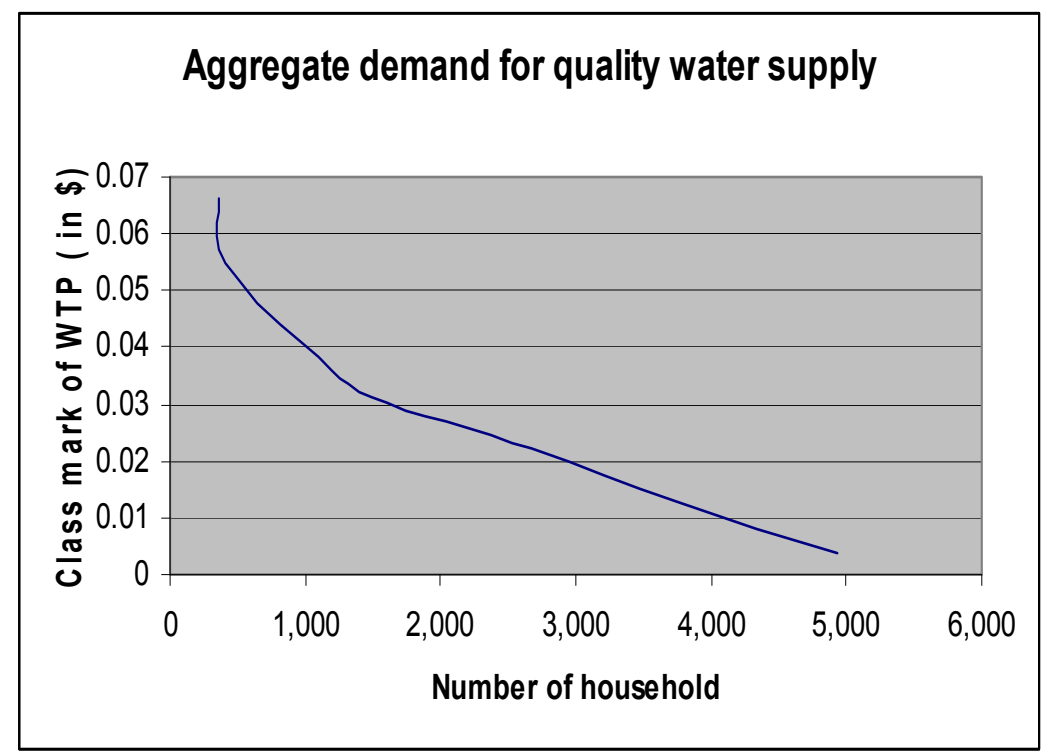

Figure 2: Estimated demand curve for improved water supply service in WSSE.

The demand schedule that has been obtained from our survey is basic information for policy makers. The information helps them to make sound water tariff decisions and investment. The information on the frequency distribution of WTP bids is also useful information in estimating the demand for improved water services in terms of the tariff versus number of households. As shown in 
figure 2, the demand curve is negatively sloped indicating the fall of the demand for improved water supply service as user charges increase, like most other economic goods, other things remaining the same. If water is considered as a free resource to the society, the consumers' surplus would be the total area under the demand curve. The area under the demand curve represents the gross value of consumers' surplus if the tariff rate is zero.

This shows the gross consumer surplus is estimated at $\$ 132.54$ if every household is using only 20 litres per day from quality water services, with supply left unrestricted. Considering the average daily water consumption of 60 litres per household the daily total consumer's surplus will be $\$ 397.60$. Further analyses also indicate the allocation of the total benefits which have been derived from the service charge fees on each household per 20 litres by implementing the quality water supply project. Current tariff rate of Oromiya Regional Government Water Resource office in Ethiopia is $\$ 0.0049$ for consumption from 0 to $3 \mathrm{M}^{3}, \$ 0.0056$ for consumption from $4-5 \mathrm{M}^{3}, \$ 0.0067$ for consumption from $6-8 \mathrm{M}^{3}, \$ 0.0081$ for consumption from $9-11 \mathrm{M}^{3}$ and $\$ 0.0099$ for consumption above $11 \mathrm{M}^{3}$ at private connections and $\$ 0.0044$ at public tap for 20 litres of water. This cost covers only the operation and maintenance cost. Thus, if the estate proposes a flat tariff rate for the new service at $\$ 0.013$ per 20 litres, which is well below the mean WTP of own survey $\$ 0.025$ per 20 litres, the inhabitants of WSSE are willing to share the cost of the estate. This helps the government in general and the estate in particular for adopting the federal water resource policy.

The total financial benefits of the quality water supply project are the sum of expected revenue of the estate, consumer's surplus to the society, and the dead weight loss. If tariff is set for water supply services, the consumers' surplus discussed previously can be minimized by shifting consumer surplus partly to dead weight loss and partly to the revenue of the estate. If a new tariff rate of $\$$ 0.013 per 20 litres is implemented the consumers' surplus (CS) decreases from $\$$ 132.53 to $\$ 72.94$ for consumption of 20 litres per day. The rest of the benefit is distributed to estate, $\$ 49.63$ in the form of revenue and $\$ 9.96$ as a dead weight loss (DWL) per 20 litres per day.

In general, the results of the study in this section open a room to federal, regional government and the estate itself in the area of improving water supply services in the sugar estate. The aggregated WTP amounts shows that the estate could collect sufficient resource for both service modernization and could also reduce existing subsidies.

\section{Conclusions}

Urban water supplies provided by public utilities are facing an acute crisis in many developing countries. As such, the urban and industrial centers of Ethiopia are also characterized by poor water supply services. At the moment, Wonji Shao Sugar Estate (WSSE) is facing unreliable and poor quality supply of water service. In this paper we used the contingent valuation method to analyze the determinants of household valuation for improved water services in WSSE. Unlike most other studies, we use the Tobit model. The result of this study 
showed that income, household size, age of the respondent, education level of the respondent, reliability of the existing water supply and respondent perception on the quality of the existing source are important variables that explain the WTP for improved water supply. Moreover, the inhabitants of the sugar estate were willing to pay more than the current water tariff rate of the federal and regional government. An important policy implication of these results is need to consider demand as opposed supply side there by adjusting pricing mechanism and considering the willingness to pay of the resident. Hence, valuation of water services is the key component of an appropriate incentive for balanced and coordinated investment development in different parts of the country. It should be noted that such studies should also complemented by other studies such as an examination of investment costs and a comparison of these costs with benefits measured using revealed, as opposed to stated preference.

\section{References}

[1] World Bank, Infrastructure for development at target, viewed at March 2008. http/target.com/World Development Report. 1994. Infrastrcture/ap 10821325353.

[2] World Health Organization and UNICEF, progress on sanitation and drinking water, Geneva, pp 1-54, 2010.

[3] Ministry of Water Resource, Federal water resource policy, Water Management Policy, Addis Ababa, pp 35-90, 1999.

[4] World Health Organization, Guidelines for drinking water quality, Health criteria and other supporting information, volume 2, Geneva, 1984.

[5] Mitchell, R.C and Carson, R.T., Using surveys to value public goods: The contingent valuation method, John Hopkins University Press: Baltimore, 1989.

[6] Hanemann, W.M., contingent valuation and economics, working paper no. 697, Department of Agricultural and Resource Economics and Policy, University of California, Berkeley, 1994

[7] Hanemann, W.M., J. Loomis \& Kanninen, B., Statistical efficiency of double bounded dichotomous choice contingent valuation, American Journal of Agricultural Economics, Vol. 73, pp 1255-63, 1994.

[8] Hanemann, W.M., (eds). Theory versus data in contingent valuation debate, The contingent valuation of environmental resources: Methodological Issues and Research Needs: Edward Elgar, 1996

[9] Green D., Jacowitz, K.E., Kahneman, D., \& MacFadden, D., Referendum contingent valuation, anchoring and willingness to pay for public goods. A paper presented at World congress of the econometric society, Tokyo, 1995.

[10] Maddala, G.S., Limited Dependent and Qualitative Variables in Econometrics. Cambridge University Press, pp 1-631, 1997.

[11] Johnston, J. and Dindaro, J., Econometric Methods. $4^{\text {th }}$ edition. New York, 1997.

[12] Long, S., Regression Models for Categorical and limited dependent Variable, 1997. 